\title{
BMJ Open Burden of early-term birth on adverse infant outcomes: a population-based cohort study in Brazil
}

\author{
Maria do Carmo Leal, ${ }^{1}$ Ana Paula Esteves-Pereira, ${ }^{1}$ Marcos Nakamura-Pereira, ${ }^{2}$ \\ Rosa Maria Soares Madeira Domingues, ${ }^{3}$ Marcos Augusto Bastos Dias, ${ }^{2}$ \\ Maria Elisabeth Moreira, ${ }^{2}$ Mariza Theme-Filha, ${ }^{1}$ \\ Silvana Granado Nogueira da Gama ${ }^{1}$
}

To cite: Leal MdC, EstevesPereira AP, Nakamura-Pereira M, et al. Burden of early-term birth on adverse infant outcomes: a population-based cohort study in Brazil. BMJ Open 2017;7:e017789. doi:10.1136/ bmjopen-2017-017789

- Prepublication history and additional material for this paper are available online. To view these files, please visit the journal online (http://dx.doi. org/10.1136/bmjopen-2017017789).

Received 17 May 2017 Revised 22 September 2017 Accepted 5 October 2017

CrossMark

${ }^{1}$ Department of Epidemiology and Quantitative Methods in Health, Women's, Children's and Adolescents' Research Group, Sérgio Arouca National School of Public Health, Oswaldo Cruz Foundation, Rio de Janeiro, Brazil

${ }^{2}$ Figueira National Institute for Women's, Children's and Adolescents Health, Oswaldo Cruz Foundation, Rio de Janeiro, Brazil

${ }^{3}$ Research Laboratory on STI/ Aids, National Institute of Infectious Diseases, 0swaldo Cruz Foundation, Rio de Janeiro, Brazil

Correspondence to Dr Rosa Maria Soares Madeira Domingues; rosa.domingues@ini.fiocruz.br

\section{ABSTRACT}

Objectives To estimate the national rate of early-term live births in Brazil and to evaluate the effect of birth at 37 and 38 weeks' gestation, as compared with 39 and 40 weeks' gestation on infant outcomes according to precursors of birth and the existence of maternal/fetal medical conditions.

Design National perinatal population-based cohort study. Setting 266 maternity services located in the five Brazilian macroregions.

Participants 18652 singleton live newborns from 37 0/7 to $406 / 7$ weeks of gestation.

Main outcome measures Resuscitation in delivery room, oxygen therapy, transient tachypnoea, admission to neonatal intensive care unit (NICU), hypoglycaemia, use of antibiotics, phototherapy, phototherapy after hospital discharge, neonatal death and breastfeeding.

Results Early terms accounted for 35\% (95\% Cl 33.4\% to $36.7 \%$ ) of all live births. Among provider-initiated births in women without medical conditions, infants of 37 and 38 weeks' gestation had higher odds of oxygen therapy (adjusted OR (AOR) 2.93, 95\% Cl 1.72 to 4.98 and AOR $1.9295 \% \mathrm{Cl} 1.18$ to 3.13), along with admission to NICU (AOR 2.01, 95\% Cl 1.18 to 3.41 and AOR 1.56, 95\% Cl 1.02 to 2.60), neonatal death (AOR $14.40,95 \% \mathrm{Cl} 1.94$ to 106.69 and $\mathrm{AOR} 13.76,95 \% \mathrm{Cl} 2.84$ to 66.75$)$, hypoglycaemia in the first 48 hours of life (AOR 7.86, 95\% Cl 1.95 to 31.71 and AOR 5.76, 95\% Cl 1.63 to 20.32), transient tachypnoea (AOR 2.98, 95\% Cl 1.57 to 5.65 and AOR 2.12, 95\% Cl 1.00 to 4.48 ) and the need for phototherapy within the first 72 hours of life (AOR 3.59, 95\% Cl 1.95 to 6.60 and AOR $2.29,95 \% \mathrm{Cl} 1.49$ to 3.53 ), yet lower odds of breastfeeding up to 1 hour after birth (AOR $0.67,95 \% \mathrm{Cl} 0.53$ to 0.86 and AOR $0.87,95 \% \mathrm{Cl} 0.76$ to 0.99 ) and exclusive breastfeeding during hospital stay (AOR 0.68, 95\% Cl 0.51 to 0.89 and AOR $0.84,95 \% \mathrm{Cl} 0.71$ to 0.99 ).

Conclusion Birth at 37 and 38 weeks' gestation increased the risk of most adverse infant outcomes analysed, especially among provider-initiated births and should be avoided before 39 weeks' gestation in healthy pregnancies.

\section{INTRODUCTION}

The timing of birth depends on the balance between the risk of continuing the pregnancy
Strengths and limitations of this study

Data from the first National Perinatal Study in Brazil with a sampling process that considered an infant demographic that spanned the whole country.

- Variables collected primarily from medical records and gestational age estimated through ultrasound scan.

- Application of non-response weights to minimise possible bias long-term outcomes estimates due to the follow-up loss.

- The study did not include hospitals with less than 500 births per year.

- Caesarean section was not classified according to clinical indication, which limited the analysis of specific conditions on neonatal outcomes.

versus the risk of delivery before term or early term. Different times of interruption have been proposed based on specific conditions. ${ }^{1}$ For uncomplicated pregnancies, different organisations, such as the American College of Obstetricians and Gynaecologists, ${ }^{2}$ the Royal College of Obstetricians and Gynaecologists ${ }^{3}$ and more recently the Brazilian National Medical Council ${ }^{4}$ have recommended that caesarean sections (CS) on maternal request, without clinical indication, be performed at 39 weeks' gestation at the earliest.

This recommendation is based on studies that have demonstrated a clear benefit in allowing the pregnancy to reach full term. Infants born at 37 and 38 weeks' gestationearly-terms - are at increased risk of adverse outcomes such as respiratory morbidities, ${ }^{5-9}$ admission to Neonatal Intensive Care Units (NICU), ${ }^{7}$ 9-12 prolonged hospitalisation, ${ }^{6}$ neonatal mortality, ${ }^{13}$ rehospitalisation, ${ }^{14}$ developmental delay ${ }^{15}$ and health complications during early infancy. ${ }^{16} 17$

However, all of these studies have been held in developed countries with lower CS rates, 
where the proportion of mothers requesting medical intervention without a clinical justification is likely to be lower. In 2014, the CS rate reached 57\% in Brazil; most of them are prelabour CS and seem not be associated with clinical or obstetric conditions. ${ }^{18-21}$

In developed countries, the pooled rate of early-term births ranged from $16.8 \%$ in Finland to $26.9 \%$ in the USA in the period 2006-2014, with decreasing rates in Norway, Sweden and the USA. ${ }^{22}$ However, the proportion of early-term births in Brazil and other developing countries is not yet known. Hence, there is a lack of a solid data concerning impact of early-term birth via CS without clinical indication on maternal and neonatal outcomes in countries with high rates of CS.

Our hypotheses are that the rate of early-term birth in Brazil is high, that a high proportion is determined by elective interruptions of the pregnancy and that it is associated with adverse neonatal outcomes.

The objectives of this study are to: (1) estimate the national rate of early-term delivery in live births in Brazil; (2) estimate the precursors of these early-term births (spontaneous or provider initiated) and (3) evaluate the effect of birth at 37 and 38 weeks' gestation compared with 39 and 40 weeks' gestation combined on neonatal outcomes according to precursors of birth and the existence of maternal/fetal medical conditions.

\section{MATERIAL AND METHODS}

\section{Data source}

The data were derived from the 'Birth in Brazil study', a national population-based cohort study of postpartum women and their newborns, conducted from February 2011 to October 2012. It had a probabilistic and complex sample designed with strata, clusters and weights and included 266 private, mixed and public maternity services located in the five Brazilian macroregions. Further information about the sample of 'Birth in Brazil study' is detailed elsewhere. ${ }^{23}$

\section{Inclusion and exclusion criteria}

In the current analysis, we included women that had given birth to a live newborn with gestational age at birth from $370 / 7$ to $406 / 7$ weeks of gestation in one of the 266 sampled maternity services during the observation period, which accounted for 18886 live births. We excluded live births from multiple pregnancies (203 newborns) and with fetal malformations potentially related to indication for CS and/or prematurity, including anencephaly, hidrocephaly, spina bifida, gastrosquisis and other abdominal wall defects, cardiac malformations and multiple malformations (31 newborns), totalling 18652 newborns in the current analysis.

\section{Predictor measures}

The primary predictor variable was gestational age at birth, 37 and 38 weeks' gestation compared with 39 and 40 weeks' gestation combined, grouped using the precursors of birth (spontaneous or provider initiated) and the existence of maternal/fetal medical conditions. Gestational age was calculated using an algorithm that primarily relied on early ultrasound estimates. ${ }^{24}$ Information on gestational age was collected from women's hospital medical records, prenatal cards and ultrasound result sheets. Priority was given to ultrasound performed between 7 and 13 weeks' gestation ( $74 \%$ of women). ${ }^{24}$ In the absence of ultrasound estimates, gestational age was based on the information reported by the woman in the interview (23\%) and lastly by the last menstrual period $(1 \%)$ and $50 \%$ centile of birth weight $(2 \%)$. Two research obstetricians independently assessed and validated the precursors of birth using information from medical records. Provider-initiated births were those triggered by an obstetric intervention (induction of labour or prelabour CS), as opposed to spontaneous births, which either initiated spontaneously or by prelabour rupture of membranes (Prom). We independently assessed the maternal/fetal conditions and obstetric complications, which were validated by two research obstetricians using information from medical records. Conditions included: hypertensive disorders (chronic hypertension, pre-eclampsia and HELLP syndrome); eclampsia; pre-existing and gestational diabetes; renal, cardiac or autoimmune diseases; the presence of severe infection at admission for birth; placental abruption; placental praevia and intrauterine growth restriction.

\section{Outcome measures}

Hospital neonatal outcomes analysed were: resuscitation in delivery room (positive pressure ventilation, orotracheal intubation, cardiac massage or use of drugs); oxygen therapy during hospitalisation (oxygen hood, continuous positive airway pressure (CPAP) or mechanical ventilation); neonatal intensive care unit admission; antibiotic use; hypoglycaemia within first 48 hours of life; phototherapy within first 72 hours of life; transient tachypnoea and breastfeeding up to 1 hour after birth and exclusive breastfeeding during hospital stay. We analysed phototherapy after hospital discharge and neonatal death as follow-up outcomes. Newborns remaining as inpatients, including those transferred to other hospitals, were tracked for up to 28 days after birth.

\section{Covariates}

Hospital and sociodemographic covariates examined as potential confounders were capacity of hospital of birth (equipped with neonatal intensive care unit, equipped with intermediate neonatal care unit only, not equipped with intensive or intermediate neonatal care unit); type of hospital for birth (baby-friendly hospital or not); whether the birth was performed in the public or private sector; mother's age $(<20,20-34, \geq 35)$; mother's years of schooling $(\leq 7,8$ to 10,11 to $14, \geq 15)$; previous births (nulliparous, 1 to 2, $\geq 3$ ); previous caesarean section (yes, no) and history of stillbirth or neonatal death (yes, no). 
Baby-friendly hospital is a WHO and Unicef global initiative to implement practices that protect, promote and support breastfeeding. Women who gave birth in public or mixed-funding hospitals but who were not covered by private health insurance plans were classified as receiving public health services/care at childbirth. Women whose birth was covered by a private health insurance plan and those who gave birth in private hospitals regardless of coverage by a health insurance plan were classified as receiving private health services/care at childbirth.

\section{Baseline data collection}

We collected baseline data concerning socioeconomic characteristics and breastfeeding via face-to-face interviews with hospitalised puerperal women. Data regarding women's obstetric history, previous and current maternal medical conditions and obstetric complications, precursors of birth and mode of birth were collected from women's hospital medical records. Neonatal outcomes were collected from children's hospital medical records.

\section{Follow-up data collection}

In the follow-up interview, we contacted women by telephone between 45 and 119 days after delivery $(n=12646$; $68 \%$ response rate) to collect data on phototherapy after hospital discharge and neonatal death that might have occurred after infants' hospital discharge.

\section{Dealing with missing data}

Proportion of missing data for exposure variables, outcomes and covariates varied from $0.0 \%$ to $5.9 \%$ (see online supplementary table 1 ). They were imputed using chained equations ${ }^{25}$ taking into account the complex sample weights. We used the fully conditional specification method in SPSS to obtain 10 imputed datasets. We then fitted our principal models based on these multiple imputed datasets using Rubin's rules to combine effect estimates and estimate standard errors. ${ }^{25} 26$

\section{Dealing with follow-up loss}

As it was not possible to contact all the women who took part in the baseline interview at the hospital $(n=12646$; $68 \%$ response rate), a logistic regression model was adjusted to estimate the probability that each woman who took part at baseline would answer the telephone interview, using a set of variables which differentiated the groups of respondents and non-respondents. Non-response adjustment factors attempt to compensate for the tendency of women having certain characteristics (such as being younger and of lower education) to respond at lower rates, affecting the probability of response in a specific stratum (see online supplementary table 2). On the basis of this model, we calculated specific sample weights for the analysis of the follow-up interview. The rationale for applying non-response weights is the assumption that non-respondents would have provided similar answers, on average, to respondents' answers for each stratum and adjustment category. Further details about the procedure for dealing with follow-up loss are on Vasconcellos $e t a l^{23}$

\section{Statistical analysis}

Post hoc calculations showed that with a significance level of 5\%, our smallest sample per stratum (1645 for spontaneous births in women with maternal or fetal conditions) would have $80 \%$ power to detect an increased risk corresponding to OR of $\geq 2$ for neonatal outcomes with prevalence's ranging from $2 \%$ to $8 \%$.

Using $\chi^{2}$ test, we analysed differences in participant characteristics, including gestational age in weeks, the precursor of birth (spontaneous or provider initiated) and maternal/fetal conditions. We performed non-conditional multiple logistic regressions, stratified by the precursor of birth and the existence of maternal/fetal conditions, to assess 37 and 38 weeks' gestation associated infant outcomes compared with infants of 39/40 weeks' gestation. We reported the estimated crude OR and adjusted OR (AOR) with 95\% CI. For all outcomes, we adjusted for capacity of hospital of birth, payment of birth, maternal age, years of schooling, parity, previous caesarean section, history of stillbirth or neonatal death and type of delivery. For both breastfeeding outcomes studied, we also adjusted for baby-friendly hospitals (yes, no). In all statistical analyses, the complex sampling design was taken into consideration. We adopted a significance level of $5 \%$ for all analyses. The statistical programme used was SPSS V.20.0.

\section{Patient involvement}

No patients were involved in setting the research question or the outcome measures nor were they involved in the design and implementation of the study. There are no plans to involve patients in dissemination.

\section{RESULTS}

Early terms accounted for $35 \%$ (95\% CI $33.4 \%$ to $36.7 \%$ ) of all 24061 live births in the 'Birth in Brazil Study'. A total of 18652 were non-malformed live births from 37 to 40 weeks' gestation-2162 of 37; 6082 of 38 and 10408 of 39 and 40 weeks' gestation combined. Of these, 12646 were followed up between 45 and 119 days after birth (mean age of 70 days) -1468 of 37; 4117 of 38 and 7061 of 39 and 40 weeks' gestation combined. Among early terms, $47 \%$ ( $95 \%$ CI $44.4 \%$ to $49.0 \%$ ) were provider initiated and $30 \%$ (95\% CI $27.9 \%$ to $31.9 \%$ ) provider initiated in women without maternal/fetal medical conditions. Compared with births at 39/40 weeks' gestation, women who had early term births were more likely to have received private healthcare, were older ( $\geq 35$ years old), had three or more previous births, a previous stillbirth or neonatal death and one or more maternal/fetal condition (table 1).

In general, the prevalence of adverse infant outcomes was higher for early-term infants for provider-initiated infants and for infants of women with maternal/fetal 
Table 1 Hospital and sociodemographic characteristics by gestational age for singleton live births

\begin{tabular}{|c|c|c|c|c|}
\hline & 37 weeks $(n=2162)$ & 38 weeks $(n=6082)$ & $39-40$ weeks $(n=10408)$ & \multirow{2}{*}{ P value* } \\
\hline & n (\%) & $\mathrm{n}(\%)$ & n (\%) & \\
\hline \multicolumn{5}{|l|}{ Capacity of hospital } \\
\hline $\begin{array}{l}\text { No intensive or intermediate neonatal } \\
\text { care unit }\end{array}$ & $319(14.8)$ & $1207(19.8)$ & $1778(17.1)$ & 0.034 \\
\hline Neonatal intermediate care unit only & $435(20.1)$ & $1241(20.4)$ & $2272(21.8)$ & \\
\hline Neonatal intensive care unit & $1408(65.1)$ & $3634(59.8)$ & $6358(61.1)$ & \\
\hline \multicolumn{5}{|l|}{ Baby-friendly initiative hospital } \\
\hline Yes & $688(31.8)$ & $1674(27.5)$ & 3597 (34.6) & $<0.001$ \\
\hline No & $1474(68.2)$ & $4416(72.6)$ & $6812(65.4)$ & \\
\hline \multicolumn{5}{|l|}{ Type of payment for birth } \\
\hline Public & $1593(73.7)$ & $4421(72.7)$ & $8549(82.1)$ & $<0.001$ \\
\hline Private & $569(26.3)$ & $1661(27.3)$ & $1860(17.9)$ & \\
\hline \multicolumn{5}{|l|}{ Age } \\
\hline $12-19$ & $383(17.7)$ & $1034(17)$ & $1945(18.7)$ & $<0.001$ \\
\hline $20-34$ & $1524(70.5)$ & $4301(70.7)$ & $7495(72)$ & \\
\hline$\geq 35$ & $254(11.7)$ & 747 (12.3) & $969(9.3)$ & \\
\hline \multicolumn{5}{|l|}{ Years of schooling } \\
\hline$\leq 7$ & $477(22.1)$ & $1683(27.7)$ & 2627 (25.2) & $<0.001$ \\
\hline $8-10$ & $530(24.5)$ & $1345(22.1)$ & $2817(27.1)$ & \\
\hline $11-14$ & $915(42.3)$ & 2389 (39.3) & $4062(39)$ & \\
\hline$\geq 15$ & $240(11.1)$ & $665(10.9)$ & $903(8.7)$ & \\
\hline \multicolumn{5}{|l|}{ Previous births } \\
\hline Nulliparous & $1026(47.5)$ & $2679(44)$ & $4925(47.3)$ & 0.015 \\
\hline $1-2$ & $922(42.6)$ & $2723(44.8)$ & 4508 (43.3) & \\
\hline$\geq 3$ & $215(9.9)$ & $679(11.2)$ & $975(9.4)$ & \\
\hline \multicolumn{5}{|l|}{ Previous caesarean section $†$} \\
\hline No & $683(60.1)$ & $1888(55.5)$ & $3294(60.1)$ & 0.001 \\
\hline Yes & $453(39.9)$ & $1515(44.5)$ & 2189 (39.9) & \\
\hline \multicolumn{5}{|l|}{ Previous stillbirth or neonatal death $\dagger$} \\
\hline No & $1042(91.8)$ & $3156(92.7)$ & $5179(94.5)$ & 0.002 \\
\hline Yes & $94(8.3)$ & $247(7.3)$ & $304(5.5)$ & \\
\hline Any medical condition & $596(27.6)$ & $1359(22.3)$ & $2145(20.6)$ & $<0.001$ \\
\hline Hypertensive disorders $\ddagger$ & $333(15.4)$ & $625(10.3)$ & $898(8.6)$ & $<0.001$ \\
\hline Eclampsia & $15(0.7)$ & $24(0.4)$ & $41(0.4)$ & 0.125 \\
\hline Pre-existing diabetes & $27(1.2)$ & $63(1.0)$ & $96(0.9)$ & 0.438 \\
\hline Gestational diabetes & $206(9.5)$ & $459(7.5)$ & $833(8.0)$ & 0.068 \\
\hline Other severe chronic diseases§ & $26(1.2)$ & $60(1.0)$ & $74(0.7)$ & 0.092 \\
\hline Infection at hospital admission for birth & $4(0.2)$ & $19(0.3)$ & $22(0.2)$ & 0.370 \\
\hline Abruptio placentae & $18(0.8)$ & $56(0.9)$ & $97(0.9)$ & 0.946 \\
\hline Placental praevia & $10(0.5)$ & $28(0.5)$ & $37(0.4)$ & 0.568 \\
\hline Intrauterine growth restriction & $119(5.5)$ & $273(4.5)$ & $457(4.4)$ & 0.263 \\
\hline \multicolumn{5}{|l|}{ Precursors of birth } \\
\hline Spontaneousף & $1219(56.4)$ & $3213(52.8)$ & $6179(59.4)$ & $<0.001$ \\
\hline Vaginal (1) & $932(76.5)$ & $2484(77.3)$ & $4933(79.8)$ & 0.024 \\
\hline Caesarean (2) & $287(23.5)$ & $729(22.7)$ & $1246(20.2)$ & \\
\hline
\end{tabular}




\begin{tabular}{|c|c|c|c|c|}
\hline & \multirow{2}{*}{$\begin{array}{l}37 \text { weeks }(n=2162) \\
n(\%)\end{array}$} & \multicolumn{2}{|c|}{38 weeks $(n=6082) 39-40$ weeks $(n=10408)$} & \multirow[b]{2}{*}{ P value } \\
\hline & & $\mathrm{n}(\%)$ & $\mathrm{n}(\%)$ & \\
\hline Provider initiated & $942(43.6)$ & $2869(47.2)$ & $4230(40.6)$ & \\
\hline Caesarean (4) & $877(93.1)$ & $2705(94.3)$ & $3811(90.1)$ & \\
\hline \multicolumn{5}{|l|}{ Mode of birth } \\
\hline Caesarean (2 and 4) & $1164(53.8)$ & $3434(56.5)$ & 5057 (48.6) & \\
\hline
\end{tabular}

${ }^{*} \chi^{2}$ tests.

†Only live births from multiparous women. $n=1136$ (37 weeks); 3403 (38 weeks); 5483 (39-40 weeks).

¥Chronic hypertension, pre-eclampsia and HELLP syndrome.

§Chronic cardiac diseases (other than hypertension), chronic renal diseases and autoimmune diseases.

ISpontaneous onset of labour or premature rupture of membranes.

HELLP, haemolysis, elevated liver enzymes and low Platelet count.

conditions. The prevalence of desirable outcomes, such as breastfeeding up to 1 hour after birth and exclusive breastfeeding during hospital stay, were lower for these newborns (table 2).

From table 3 to table 5, we analysed infant outcomes associated with early-term birth stratified by the precursors of birth and the existence of maternal/fetal conditions.

For infants of women with provider-initiated birth and without a maternal/fetal condition, the necessity of oxygen therapy increased both at 37 and 38 weeks (AOR 2.93, 95\% CI 1.72 to 4.98 and AOR 1.92, 95\% CI 1.18 to 3.13 ), along with admission to NICU (AOR 2.01, 95\% CI 1.18 to 3.41 and AOR 1.56, 95\% CI 1.02 to 2.60) and neonatal death (AOR 14.40, 95\% CI 1.94 to 106.69 and AOR $13.76,95 \%$ CI 2.84 to 66.75 ) (table 3). For provider-initiated birth in women with maternal/fetal conditions, risks for oxygen therapy and admission to NICU were increased for infants at 37 weeks only (table 3 ).

Risks also increased at both 37 and 38 weeks for infants of women with provider-initiated birth and without a maternal/fetal condition for hypoglycaemia in the first 48 hours of life (AOR 7.86, 95\% CI 1.95 to 31.71 and AOR 5.76, 95\% CI 1.63 to 20.32), transient tachypnoea (AOR 2.98, 95\% CI 1.57 to 5.65 and AOR $2.12,95 \%$ CI 1.00 to 4.48 ) and the need for phototherapy within the first 72 hours of life (AOR 3.59, 95\% CI 1.95 to 6.60 and AOR 2.29, 95\% CI 1.49 to 3.53 ), (table 4). Infants born spontaneously at 37 weeks were more likely to need phototherapy after hospital discharge regardless of maternal/fetal conditions, while for the ones born provider-initiated, both 37 and 38 weeks were more likely to need it, although only for women with maternal/fetal conditions (table 4).

Among women with spontaneous birth onset, infants born at 37 weeks were less likely to be breastfed up to 1 hour after birth and to be exclusively breastfed during hospital stay, regardless of maternal/fetal conditions. While among provider-initiated births, both infants of 37 and 38 weeks, when compared with their counterparts, were less likely to have followed these hospital practices regardless of maternal/fetal conditions (table 5).

\section{DISCUSSION}

\section{Principal findings}

More than a third of all live births in Brazil were early term. Almost half of them were provider initiated, mainly via prelabour CS, and $30 \%$ were provider initiated in women without clinical or obstetric conditions. Among provider-initiated births, early-term infants had an increased likelihood of several mild and severe adverse outcomes such as breastfeeding delay, transient tachypnoea, hypoglycaemia, phototherapy, neonatal intensive care unit admission and neonatal death, especially in women without clinical or obstetric conditions.

\section{Results in relation to other studies}

The rate of provider initiated among early-term births in our study $(46.7 \%)$ was as high as those previously reported in developed countries, like Canada (45.2\%), USA $(42.4 \%)$ and Denmark $(41.8 \%) .^{22}$ However, Brazilian early-term birth rate $(35 \%)$ was the double of the rates observed in northern countries of Europe, such as Denmark (18.1\%), Finland (17.4\%), Sweden (18.5\%) and Norway $(16.8 \%)$ and considerably higher than in Canada $(25.3 \%)$ and the USA $(24.4 \%){ }^{22}$ Developed countries have prelabour caesarean rates in the earlyterm group close to 20\% (Canada, Denmark, Norway, Sweden, USA), ${ }^{22}$ while our study found more than $40 \%$.

The high proportion of provider-initiated early-term birth not related to clinical conditions is consistent with previous studies in Brazil that identified non-clinical factors as the most common determinants of prelabour CS. ${ }^{18-2127}$ Similarly, a study in the USA have also shown a significant number of prelabour CS with no recorded clinical indication. ${ }^{13}$ Considering approximately 3000000 live births per year in Brazil, we estimate that more than 


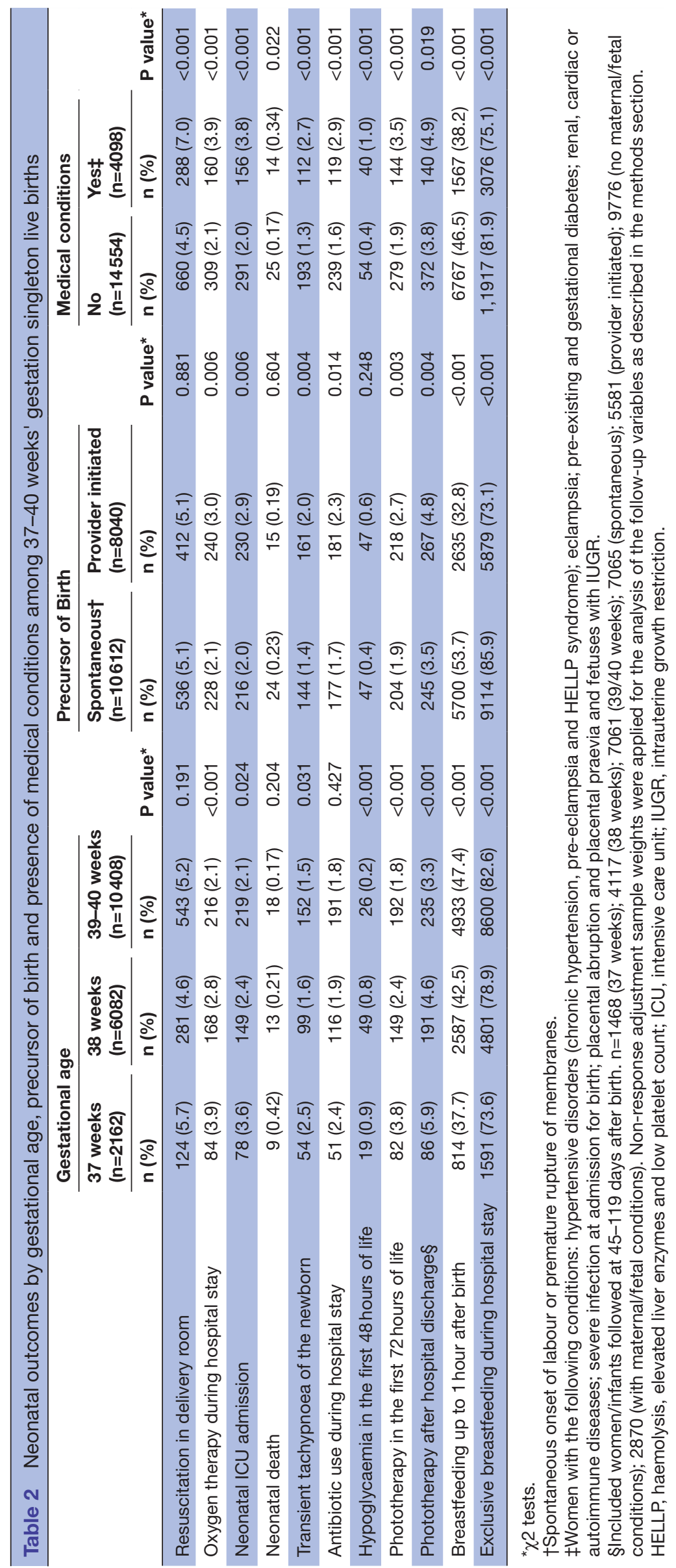




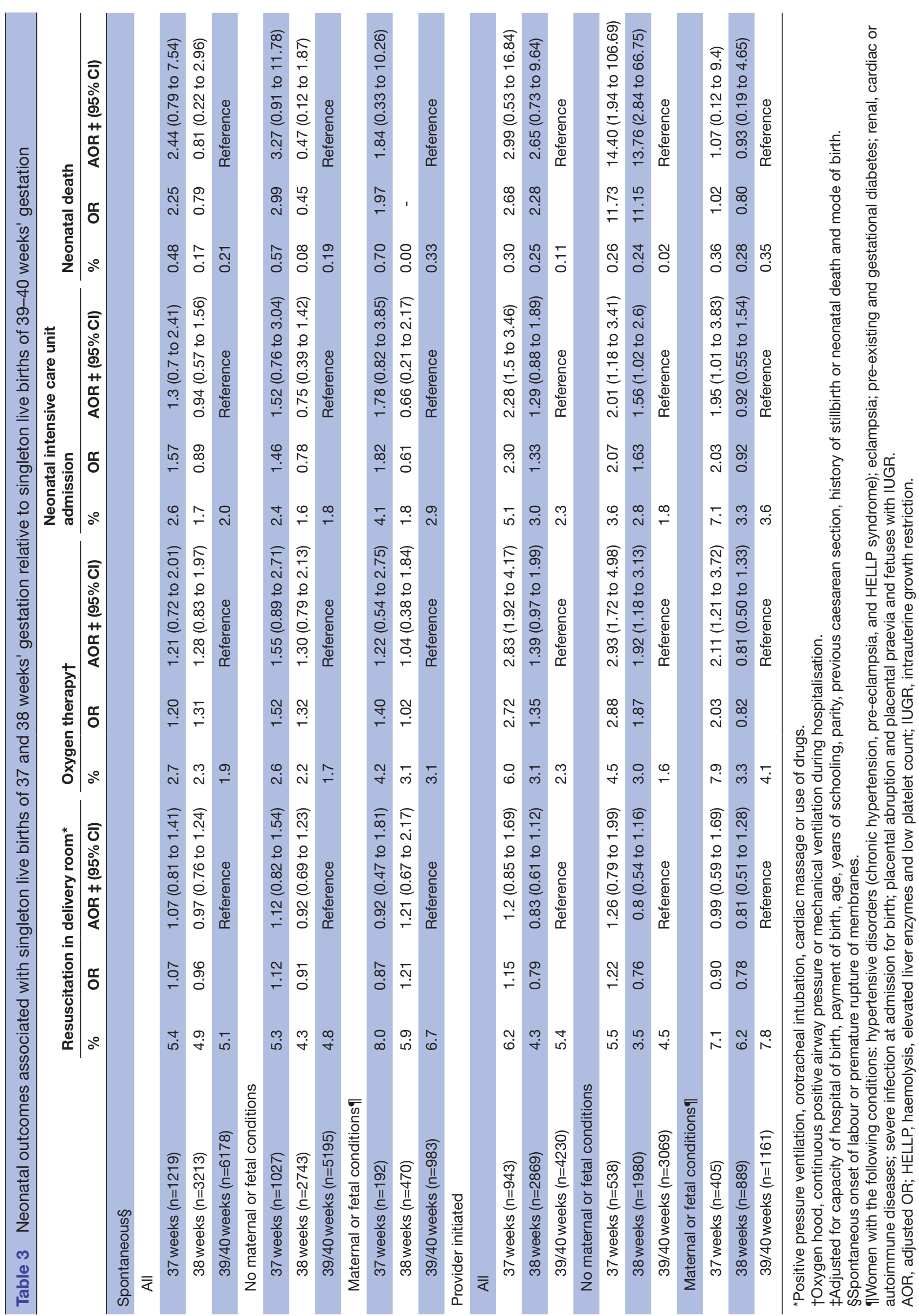




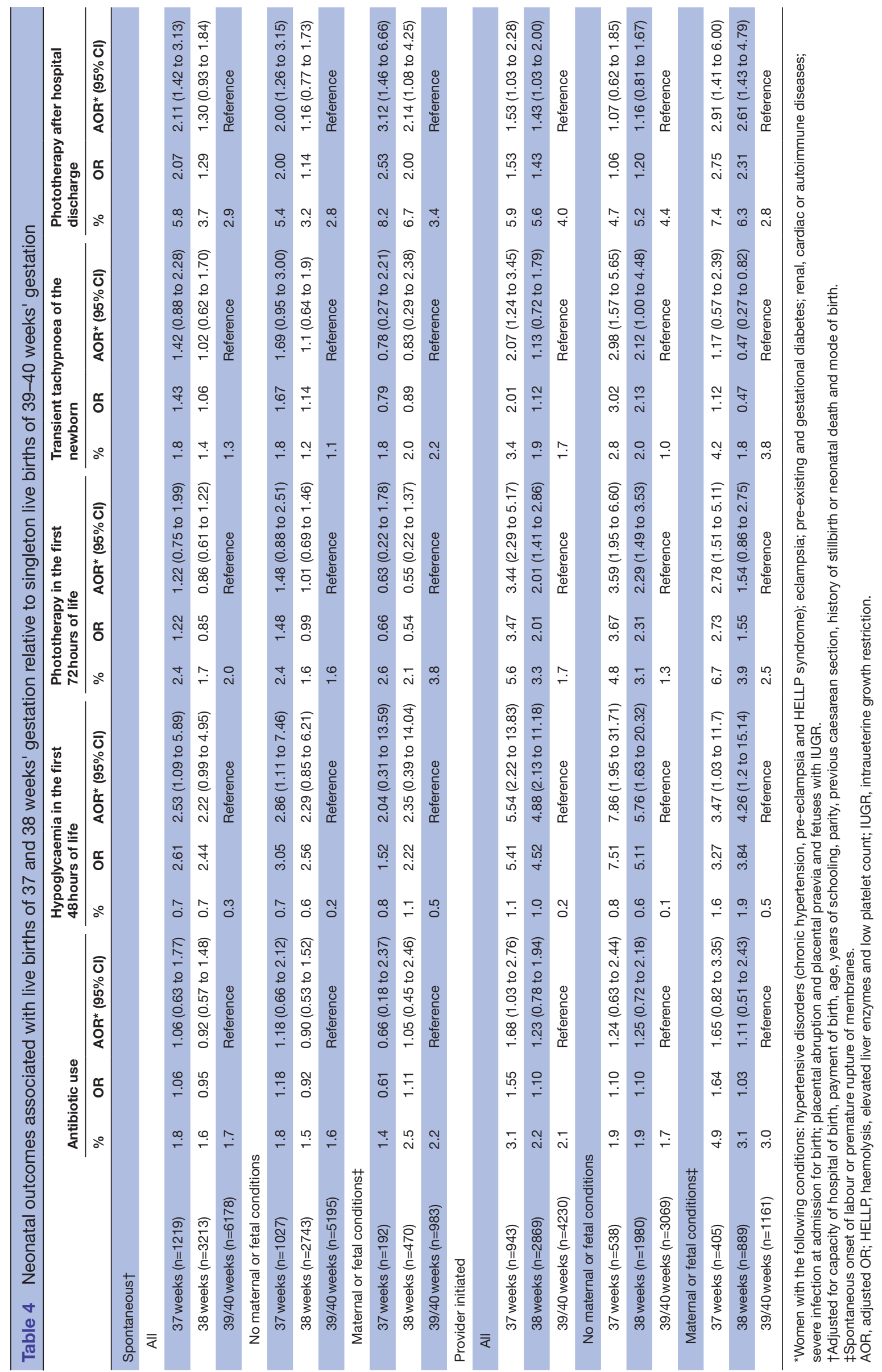


Table 5 Breastfeeding practices associated with live births of 37 and 38 weeks' gestation relative to singleton live births of 39-40 weeks' gestation

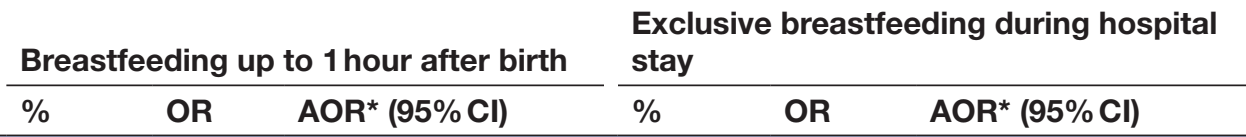

Spontaneous†

All

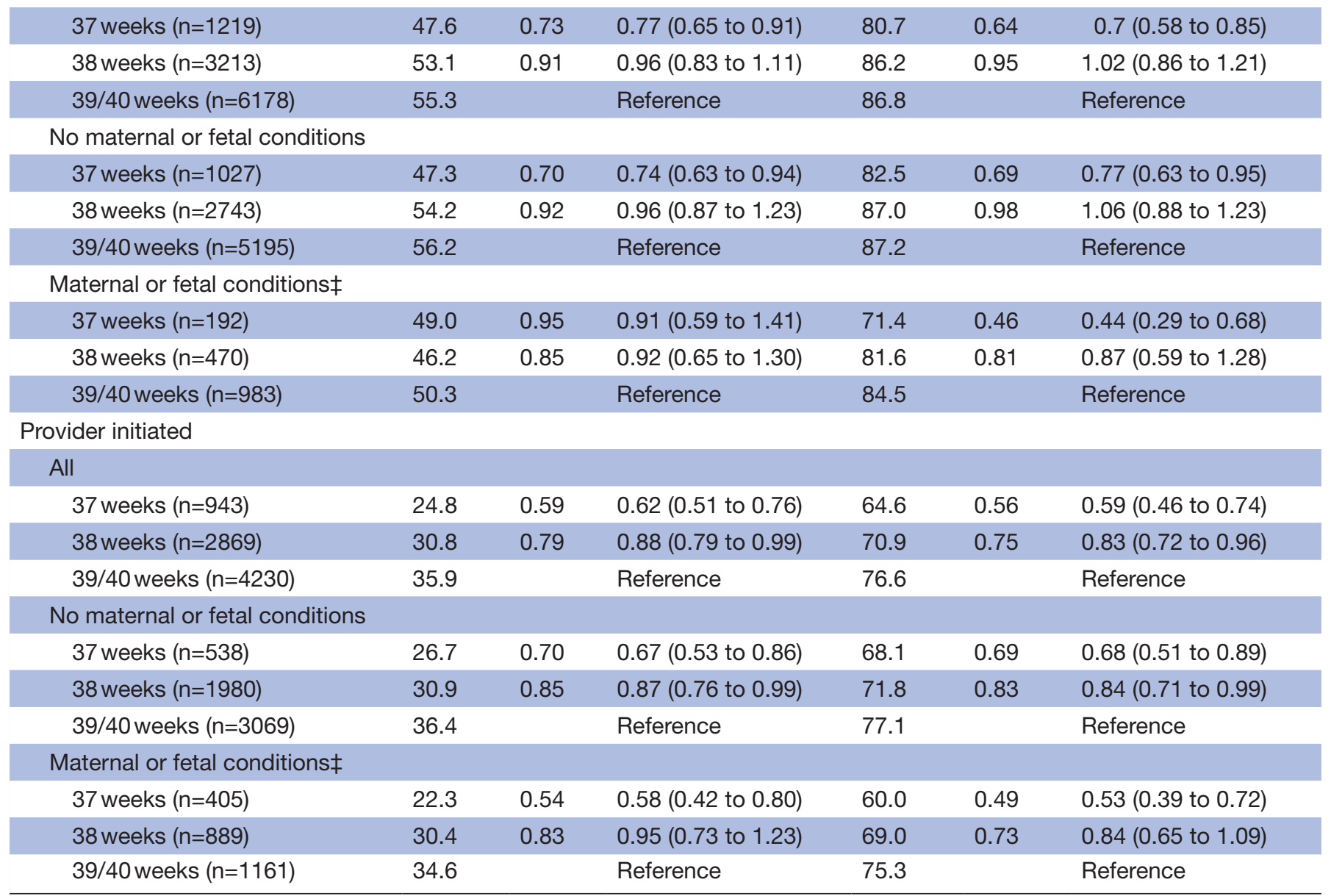

*Adjusted for capacity of hospital of birth, if baby-friendly initiative hospital, payment of birth, age, years of schooling, parity, previous caesarean section, history of stillbirth or neonatal death and mode of birth.

†Spontaneous onset of labour or premature rupture of membranes.

¥Women with the following conditions: hypertensive disorders (chronic hypertension, pre-eclampsia and HELLP syndrome); eclampsia; pre-existing and gestational diabetes; renal, cardiac or autoimmune diseases; severe infection at admission for birth; placental abruption and placental praevia and fetuses with IUGR.

AOR, adjusted OR; HELLP, haemolysis, elevated liver enzymes and low platelet count; IUGR, intrauterine growth restriction.

300000 of these births are early-term provider-initiated $\mathrm{CS}$ in cases where women show no sign of medical complication $(35 \%$ early term $\times 30 \%$ provider initiated in women without maternal/fetal conditions $\times 3000000$ live births).

We found higher rates of adverse neonatal outcomes in early-term infants when compared with births at 39-40 weeks' gestation. The higher risk in infants born at 38 weeks when compared with full-term infants is controversial in the scientific literature. Recent papers have reported similar rates of adverse outcomes in infants born at 38 weeks when compared with full-term infants, ${ }^{28} 29$ but other authors ${ }^{81130}$ have reported increased rates of adverse neonatal outcomes even when the birth occurred a few days before the 39th week of gestation. ${ }^{11}$ In our study, early-terms infants born at 37 weeks had the highest rates of adverse neonatal outcomes but we also observed an increased risk for early-term infants born at 38 weeks. Higher rates of adverse neonatal outcomes were also observed in provider-initiated early-term births in comparison with spontaneous early-term births. The association of early-term CS with adverse neonatal outcomes has been frequently reported, both in primary ${ }^{8}$ and repeated CS. ${ }^{112830}$ The rate of adverse neonatal outcomes among provider-initiated early-term births was higher in cases where clinical/obstetric conditions were present. These observations demonstrated the independent effect of 
these morbidities on the adverse neonatal outcomes. ${ }^{7} 31$ However, the strongest association between gestational age and neonatal adverse outcomes was found for provider-initiated births among women who did not have any clinical or obstetric condition. Among the provider-initiated births in women without maternal/fetal complications, early terms were associated with increased odds of occurrence of adverse neonatal outcomes, ranging from 1.63 for admission in NICU to 11.15 for neonatal death, in births at 38 weeks, along with even higher odds in births at 37 weeks. For spontaneous births, higher rates of admission to NICU were observed in births at 37 weeks' gestation. Similar results were observed in two retrospective cohorts in the USA that reported higher rates of NICU or neonatology service admission among early-term vaginal births when compared with full-term neonates. ${ }^{99}$

Our results showed lower rates of breastfeeding practices during hospital stay in provider-initiated births even when at full term: provider-initiated births at 39/40 weeks were less likely to be breastfed than early-term spontaneous births at 37 or 38 weeks' gestation. These results demonstrate the negative effect of CS on breastfeeding practices.

\section{Strengths and limitations}

Strengths of this study include the fact it was the first National Perinatal Study in Brazil with a sampling process that considered an infant demographic that spanned the whole country, including all macroregions and all types of health services. We involved a large number of women and newborns, enabling analysis of the intrinsic effect of gestational age, precursors of birth and the presence of maternal/fetal pathologies on neonatal outcomes. Other study strengths include the careful measurement of variables, collected primarily from medical records and gestational age estimates, of which the majority were calculated using an ultrasound $\operatorname{scan}^{24}$ and analysis of subsequent outcomes such as phototherapy after hospital discharge. As we have stratified the analysis by gestational age, precursors of birth and presence of maternal and fetal conditions, the results are largely generalisable, especially for middle-income countries. It should be noted, however, that the results of the provider-initiated group are a reflection of the large number of antepartum caesareans in this group, and a population with a higher proportion of inductions may mitigate the effect of GA on some neonatal outcomes.

A limitation of the study was that it did not include hospitals with less than 500 births per year; therefore, the estimates presented here are not applicable to these small hospitals. However, it is possible that small hospitals have poorer infrastructure and the consequences of earlyterm birth at these hospitals could be even worse. CS was not classified according to clinical indication, which limited the analysis of specific conditions on neonatal outcomes. We also used data of clinical and obstetric conditions collected at the hospital from medical records as evidence of the presence of these conditions. This criterion influenced results, making them more sensitive but less specific classification, which may have led to an overestimation of the presence of complications. Moreover, the study did not allow for the distinction between mild and severe complications, which could have limited the comparison between groups with and without clinical/obstetric conditions. Another limitation would be the smaller amount of resources of some hospitals in Brazil, which could attenuate the relationship of precursors to those with outcomes that require technology, such as oxygen therapy, neonatal intensive care admission and phototherapy.

To account for follow-up loss, we applied non-response weights to minimise possible bias of the long-term outcomes estimates. Sample weights may reduce bias but often increase the variance of weighted estimators. A solution was to use the method of quintiles of the predicted response probabilities to define five weight adjustment classes in which a response rate was estimated, while keeping the increase in weight variation to a minimum.

\section{CONCLUSION}

In Brazil, early-term infants made up $35 \%$ of live births, with more than 300000 infants unnecessarily being born early term each year. Both studied exposures, early term and provider-initiated birth, contributed to poorer infant outcomes likely resulting in increased costs of healthcare. Provider-initiated early-term birth seems to be even more disadvantageous when performed in women without maternal/fetal medical conditions. Given the current increase in the CS rate worldwide, these results are likely to be applicable in an international context.

Acknowledgements We thank the regional and state coordinators, supervisors, data collectors, and all of the staff at the participating health facilities from 'Birth in Brazil" Study. We also thank the mothers who participated and made this study possible.

Contributors MCL, APE-P and MN-P designed the study, analysed and interpreted the data, wrote, revised, read and approved the final version of the manuscript. RD, MABD, MEM, MF, SGNG collaborated in the data analysis, wrote, revised, read and approved the final version of the manuscript.

Funding This work was supported by the Ministério da Ciência, Tecnologia e Inovação - Conselho Nacional de Desenvolvimento Científico e Tecnológico; Fundação Carlos Chagas Filho de Amparo à Pesquisa do Estado do Rio de Janeiro and Fundação Oswaldo Cruz. The funders had no role in study design, data collection and analysis, decision to publish or preparation of the manuscript.

Competing interests None declared.

\section{Patient consent Obtained.}

Ethics approval This study was carried out in accordance with the National Health Council Resolution n. 196/96. The ethics committee of the Sérgio Arouca National School of Public Health, Oswaldo Cruz Foundation (CEP/ENSP) approved this study under the research protocol CAAE: 0096.0.031.000-10 (approval date: May 11th 2010). Before starting the baseline interview, the interviewer read aloud the Free and Informed Consent Form and received written consent of the interviewee. The participant then received a copy containing all details of the research, including the contact of the national and state coordinators. All hospital directors also gave written informed consent.

Provenance and peer review Not commissioned; externally peer reviewed.

Data sharing statement Data of Birth in Brazil Study can be shared for specific research questions that are available from the corresponding author on request. 
Open Access This is an Open Access article distributed in accordance with the Creative Commons Attribution Non Commercial (CC BY-NC 4.0) license, which permits others to distribute, remix, adapt, build upon this work non-commercially, and license their derivative works on different terms, provided the original work is properly cited and the use is non-commercial. See: http://creativecommons.org/ licenses/by-nc/4.0/

(c) Article author(s) (or their employer(s) unless otherwise stated in the text of the article) 2017. All rights reserved. No commercial use is permitted unless otherwise expressly granted.

\section{REFERENCES}

1. Spong CY, Mercer BM, D'alton M, et al. Timing of indicated latepreterm and early-term birth. Obstet Gynecol 2011;118:323-33.

2. Anon. ACOG committee opinion no. 559: Cesarean delivery on maternal request. Obstet Gynecol 2013;121:904-7.

3. NICE. National Institute for Health and Care Excellence. Caesarean section. Clinical guideline, 2011.

4. BRAZIL. Conselho Federal de Medicina. ResoluÇÃo $N^{\circ} 2.144$, De 17 De MarÇo De, 2016.

5. Hansen AK, Wisborg K, Uldbjerg N, et al. Risk of respiratory morbidity in term infants delivered by elective caesarean section: cohort study. BMJ 2008;336:85-7.

6. Engle WA, Kominiarek MA. Late preterm infants, early term infants, and timing of elective deliveries. Clin Perinatol 2008;35:325-41.

7. Brown HK, Speechley KN, Macnab J, et al. Neonatal morbidity associated with late preterm and early term birth: the roles of gestational age and biological determinants of preterm birth. Int $J$ Epidemiol 2014;43:802-14.

8. Prefumo F, Ferrazzi E, Di Tommaso M, et al. Neonatal morbidity after cesarean section before labor at 34(+0) to $38(+6)$ weeks: a cohort study. J Matern Fetal Neonatal Med 2016;29:1334-8.

9. Sengupta S, Carrion V, Shelton J, et al. Adverse neonatal outcomes associated with early-term birth. JAMA Pediatr 2013;167:1053-9.

10. Clark SL, Frye DR, Meyers JA, et al. Reduction in elective delivery at $<39$ weeks of gestation: comparative effectiveness of 3 approaches to change and the impact on neonatal intensive care admission and stillbirth. Am J Obstet Gynecol 2010;203:449-446.

11. Tita AT, Landon MB, Spong CY, et al. Timing of elective repeat cesarean delivery at term and neonatal outcomes. $N$ Engl J Med 2009;360:111-20.

12. Bailey BA, McCook JG, Chaires C. Burden of elective early-term births in rural Appalachia. South Med J 2014;107:624-9.

13. Reddy UM, Ko CW, Raju TN, et al. Delivery indications at latepreterm gestations and infant mortality rates in the United States. Pediatrics 2009;124:234-40.

14. Dietz PM, Rizzo JH, England LJ, et al. Early term delivery and health care utilization in the first year of life. $J$ Pediatr 2012;161:234-9.
15. Schonhaut L, Armijo I, Pérez M. Gestational age and developmental risk in moderately and late preterm and early term infants. Pediatrics 2015;135:e835-e841.

16. Boyle EM, Poulsen G, Field DJ, et al. Effects of gestational age at birth on health outcomes at 3 and 5 years of age: population based cohort study. BMJ 2012;344:e896.

17. Edwards MO, Kotecha SJ, Lowe J, et al. Early-term birth is a risk factor for wheezing in childhood: A cross-sectional population study. J Allergy Clin Immunol 2015;136:581-7.

18. Nakamura-Pereira M, do Carmo Leal M, Esteves-Pereira AP, et al Use of Robson classification to assess cesarean section rate in Brazil: the role of source of payment for childbirth. Reprod Health 2016;13:128.

19. Domingues RM, Dias MA, Nakamura-Pereira M, et al. Process of decision-making regarding the mode of birth in Brazil: from the initial preference of women to the final mode of birth. Cad Saude Publica 2014;30(Suppl 1):S1-16.

20. Barros AJ, Santos IS, Matijasevich A, et al. Patterns of deliveries in a Brazilian birth cohort: almost universal cesarean sections for the better-off. Rev Saude Publica 2011;45:635-43.

21. Potter JE, Hopkins K, Faúndes A, et al. Women's autonomy and scheduled cesarean sections in Brazil: a cautionary tale. Birth 2008;35:33-40.

22. Richards JL, Kramer MS, Deb-Rinker P, et al. Temporal trends in late preterm and early term birth rates in 6 high-income Countries in North America and Europe and association with clinician-initiated obstetric interventions. JAMA 2016;316:410-9.

23. Vasconcellos MT, Silva PL, Pereira AP, et al. Sampling design for the birth in Brazil: National survey into labor and birth. Cad Saude Publica 2014;30(Suppl 1):S1-10.

24. Pereira AP, Leal MC, da Gama SG, et al. Determining gestational age based on information from the birth in Brazil study. Cad Saude Publica 2014;30(Suppl 1):S1-12.

25. White IR, Royston P, Wood AM. Multiple imputation using chained equations: issues and guidance for practice. Stat Med 2011;30:377-99.

26. Rubin D. Multiple imputation for nonresponse in surveys. Hoboken, NJ: J Wiley, 1987.

27. Leal MC, Esteves-Pereira AP, Nakamura-Pereira M, et al. ProviderInitiated Late Preterm Births in Brazil: Differences between Public and Private Health Services. PLOS One 2016;11:e0155511.

28. Ganchimeg T, Nagata C, Vogel JP, et al. Optimal timing of delivery among low-risk women with prior caesarean section: a secondary analysis of the WHO multicountry survey on maternal and newborn health. PLoS One 2016;11:e0149091.

29. Parikh LI, Reddy UM, Männistö T, et al. Neonatal outcomes in early term birth. Am J Obstet Gynecol 2014;211265:e261:265e211.

30. Chiossi G, Lai Y, Landon MB, et al. Timing of delivery and adverse outcomes in term singleton repeat cesarean deliveries. Obstet Gynecol 2013;121:561-9.

31. Parikh L, Singh J, Timofeev J, et al. Timing and consequences of early term and late term deliveries. J Matern Fetal Neonatal Med 2014;27:1158-62. 